\title{
Dukungan Keluarga dan Manajemen Hipertensi
}

\author{
Sri Wahyuni \\ Program Studi S1 Keperawatan, Fakultas Ilmu Kesehatan, \\ Universitas Muhammadiyah Jember, Jl. Karimata No. 49 Kecamatan Sumbersari, \\ Jember, Jawa Timur \\ Email: sriwahyuni@unmuhjember.ac.id \\ Diterima : 3 November 2020 \\ Disetujui : 30 November 2020 \\ Dipublikasikan : 10 Desember 2020
}

\begin{abstract}
Abstrak
Latar Belakang dan Tujuan: Manajemen hipertensi sangat penting dilakukan untuk meningkatkan keberhasilan pengobatan hipertensi dan mencegah komplikasi. Penelitian ini ingin mengetahui hubungan dukungan keluarga dengan manajemen hipertensi.

Metode: Metode deskriptif dengan studi cross-sectional yang dilakukan terhadap klien hipertensi di wilayah kerja Puskesmas Sukowono sejumlah 50 klien dengan menggunakan teknik stratified random sampling.

Hasil: Hasil penelitian diketahui bahwa rata-rata usia pasien hipertensi 47.14 tahun (antara 44.49-49.79 tahun). Laki-laki 22 (44\%) dan perempuan 28 (56\%). Mayoritas responden suku madura (87.2\%), sudah menikah (100\%), berpendidikan hanya tamat SD (70\%), dan pekerjaan ibu rumah tangga $(48 \%)$. Dukungan keluarga mayoritas rendah (52\%) dan 67\% pasien hipertensi tidak melakukan manajemen hipertensi dengan baik. Klien hipertensi dengan dukungan keluarga baik, mempunyai manajemen hipertensi lebih baik dibandingkan klien hipertensi dengan dukungan keluarga kurang ( $p$ value $<0.05$ ).

Simpulan dan Implikasi: Dukungan keluarga yang rendah diketahui menjadi salah satu faktor rendahnya manajemen hipertensi pada pasien, sehingga berdampak pada rendahnya angka keberhasilan pengobatan hipertensi atau menjadi hipertensi yang tidak terkontrol. Salah satu strategi yang dapat dilakukan adalah mengoptimalkan dukungan keluarga.
\end{abstract}

Kata Kunci: Dukungan keluarga; Hipertensi; Perawatan diri hipertensi

Sitasi: Wahyuni, S. (2020). Dukungan keluarga dan manajemen hipertensi. The Indonesian Journal of Health Science. 12(2), 199-208

Copyright: ( $) 2020$ Wahyuni. This is an open-access article distributed under the terms of the Creative Commons Attribution-NonCommercial 4.0 International License, which permits unrestricted use, distribution, and reproduction in any medium, provided the original author and source are credited.

Diterbitkan Oleh: Universitas Muhammadiyah Jember

ISSN (Print): 2087-5053

ISSN (Online): 2476-9614 


\begin{abstract}
Background and Aim: Management of hypertension is very important to do to improve the success of hypertension treatment and prevent complications. The study assesed association between family support and management of hypertension.

Methods: The study methode was descriptive cross-sectional study, consenting 50 adults patients who was diagnosed with hypertension in Sukowono Public Health Center. Sampling technique used stratified random sampling.

Results: The results showed that the mean age of the patients was 58.12 years (range 55.40-60.84years). There were 22 (44\%) males and 28 (56\%) females. Most respondents were Madura (86\%), married (96\%), had primary education (70\%) and housewifes work. Most (52\%) had poor family support and 58\% patients had poor management of hypertension. Patients with good family support had better hypertension management compared to those with poor family support ( $p$ value <0.05).

Conclusion: Poor family support was identified as causes of poor management of hypertension, so that the impact on the low success rate of treating hypertension or becoming uncontrolled hypertension. One strategy that can be done is to optimize family support.
\end{abstract}

Keywords: Family support; Hypertension; Management of hypertension

\section{PENDAHULUAN}

Hipertensi atau tekanan darah tinggi merupakan masalah kesehatan global utama yang paling banyak terjadi pada semua wilayah di seluruh dunia (Hedner, et.al, 2012). Sekitar $31,1 \%$ dari populasi orang dewasa dunia hidup dengan hipertensi, dan $28,5 \%$ berada di negara berpenghasilan tinggi, sementara $31,5 \%$ berada di negara berpenghasilan rendah dan menengah (Milss, et.al, 2016). Menurut World Health Organization (WHO) dan The International Society of Hypertension (ISH), terdapat 600 juta penderita hipertensi di seluruh dunia, dengan 3 juta diantaranya meninggal setiap tahunnya. Tujuh dari setiap 10 penderita tersebut tidak mendapatkan pengobatan secara adekuat.

Hipertensi dapat menyebabkan komplikasi berupa penyakit jantung koroner, infark (penyumbatan pembuluh darah yang menyebabkan kerusakan jaringan) jantung (54\%), stroke (36\%), dan gagal ginjal (32\%) (WHO, 2013). Survei faktor risiko penyakit kardiovaskular (PKV) oleh proyek WHO pada data Riskesdas (2018) menunjukan angka prevalensi hipertensi di Indonesia sebesar $34,1 \%$, dengan tekanan darah diatas 140/90 mmHg pada dua kali pengukuran dan pada keadaan cukup istirahat. Berdasarkan survei tersebut, terlihat bahwa hipertensi masih menjadi permasalahan dan akan semakin meningkat seiring dengan komplikasi dari hipertensi.

Tingginya angka kejadian hipertensi akan mempengaruhi derajat kesehatan masyarakat. Hipertensi memberikan dampak negatif terhadap fisik, psikologis, ekonomi dan sosial. Hipertensi memiliki dampak yang signifikan pada peningkatan risiko penyakit 
kronis dan dinyatakan bahwa hipertensi meningkatkan risiko infark myocard, penyakit ginjal, stroke dan gagal jantung (Kabacki, 2010). Hipertensi persisten dapat mengarah pada kondisi gagal ginjal terminal atau End Stage Renal Failure (ESRF) dimana $80-90 \%$ pasien diharuskan menjalani cuci darah (Whitworth, 2005). Black \& Hawks (2014) menyatakan hipertensi merupakan faktor resiko utama untuk terjadinya masalah kesehatan seperti stroke, infark miokard, gagal jantung, aneurisma arteri, penyakit arteri perifer dan penyakit ginjal kronik.

Permasalahan tersebut akan terus muncul apabila terapi yang dilakukan oleh pasien hipertensi tidak teratur. Sebagaimana kita tahu terapi hipertensi bersifat kontinu dengan tujuan untuk mempertahankan kadar tekanan darah yang normal dan harus disertai dengan perubahan gaya hidup. Progresivitas menuju hyperetension related disease akan meningkat seiring dengan ketidakteraturan dalam mengonsumsi obat anti hipertensi.

Hipertensi biasanya merupakan kondisi seumur hidup, membutuhkan pengobatan berkelanjutan. Manajemen hipertensi melibatkan usaha harian yang substansial, termasuk konsumsi obat antihipertensi, pemantauan tekanan darah, dan modifikasi aktivitas fisik, diet, dan kebiasaan sehari-hari lainnya (Chobanian, et.al, 2003). Perubahan gaya hidup yang demikian dan mekanisme koping terhadap manajemen hipertensi, dapat menyebabkan pasien berisiko mengalami gangguan mental (Hamer, et.al, 2010; Johansen, et.al, 2012). Mengingat kompleksitas manajemen hipertensi dan tingginya risiko untuk mengalami gangguan mental, banyak pasien hipertensi mungkin membutuhkan dukungan untuk mengelola tekanan darah mereka dengan sukses. Seperti dukungan dari keluarga, teman, dan tenaga profesional.

Tingkat dukungan keluarga secara signifikan terkait dengan penurunan tekanan darah (Connel \& Moseley, 2005). Hasil penelitian kualitatif oleh Widihastuti (2010) menyatakan bahwa banyak orang yang tidak mengubah pola diet, meskipun mereka sudah terdiagnosa hipertensi. Alasan yang menyebabkan pasien tidak mengubah perilakunya adalah kurangnya perhatian dari keluarga mengenai manajemen hipertensi. Oleh karena itu, keluarga diperlukan untuk membantu pasien dalam menerapkan manajemen nonfarmakologis hipertensi.

\section{METODE PENELITIAN}

Desain $\begin{array}{r}\text { penelitian } \\ \text { deskriptif }\end{array}$
menggunakan desain studi cross-sectional
dengan suesioner terstruktur
menggunakan kue
untuk mengukur dukungan keluarga
dan manajemen hipertensi. Penelitian
ini dilakukan di wilayah kerja
Puskesmas Sukowono Kabupaten
Jember. Sampel penelitian yaitu
klien hipertensi sejumlah 50 orang
dengan menggunakan stratified
random sampling. Melalui metode
tersebut, dari 8 desa sampel dipilih
sesuai dengan strata yang telah
ditentukan, kemudian dari strata
yang telah ditentukan, dipilih secara
acak untuk menentukan sampel.
Pengumpulan data dilakukan bulan
Mei sampai dengan Juni Tahun 2019.
Penelitian ini telah mendapatkan


persetujuan etik dari Komite Etik Penelitian Fakultas Ilmu Kesehatan Universitas Muhammadiyah Jember dengan nomor 310/KEPK/FIKES/III/2019. Setelah data terkumpul, maka dilanjutkan dengan analisis data. Uji statistik menggunakan korelasi spearman rho dengan tingkat kemaknaan 95\% ( $\alpha$ 0.05). yang diuji dengan SPSS 23.0.

\section{HASIL}

Tabel 1 menunjukkan bahwa rata-rata usia pasien hipertensi adalah 58.12 tahun, mayoritas diantara usia 40 - 60 tahun $(n=30,60 \%)$, jenis kelamin perempuan $(\mathrm{n}=41,82 \%)$, agama islam $(\mathrm{n}=50,100 \%)$, suku madura $(n=43,86 \%)$, dan status perkawinan menikah $(\mathrm{n}=48,96 \%)$. Dari total responden, 35 (70\%) berpendidikan sekolah dasar, mayoritas bekerja sebagai petani 35 (70\%), sebagian besar memiliki riwayat keluarga dengan hipertensi 31 (62\%), mengalami hipertensi lebih dari 2 tahun 23 (46\%) dan sebagian besar tidak pernah mendapat informasi kesehatan mengenai hipertensi 33 (66\%).

Berdasarkan tabel 2 diketahui bahwa pasien yang memiliki dukungan keluarga baik, melakukan manajemen hipertensi dengan baik 24 (48\%), dan hanya terdapat 2 pasien yang kurang baik dalam melakukan manajemen hipertensi (4\%). Sedangkan pasien yang memiliki dukungan keluarga kurang ternyata mayoritas juga melakukan manajemen hipertensi kurang 22 (44\%), dan hanya 2 (4\%) yang melakukan manajemen hipertensi dengan baik.

Berdasarkan hasil uji statistik Rank Spearman diperoleh nilai $P$ value $0,02<0,05$ sehingga dapat dikatakan terdapat hubungan yang signifikan antara dukugan keluarga dengan manajemen hipertensi, artinya klien hipertensi dengan dukungan keluarga baik, mempunyai manajemen hipertensi lebih baik dibandingkan klien hipertensi dengan dukungan keluarga kurang. Semakin baik dukungan keluarga maka semakin baik pula manajemen hipertensi yang dilakukan oleh klien hipertensi.

\section{PEMBAHASAN}

Penelitian ini mengeksplor tingkat dukungan keluarga dan bagaimana pengaruhnya terhadap manajemen hipertensi klien yang mengalami hipertensi. Dari seluruh responden, diketahui bahwa $48 \%$ mempunyai manajemen hipertensi yang kurang baik. Rendahnya manajemen hipertensi berhubungan dengan peningkatan hipertensi yang tidak terkontrol (Ademe, Aga \& Gela, 2019). Penelitian terdahulu menunjukkan bahwa terjadi peningkatan angka hipertensi yang tidak terkontrol (Stabile, et.al, 2017). Rendahnya manajemen hipertensi juga berkontribusi terhadap meningkatnya komplikasi hipertensi sendiri seperti masalah renovaskular seperti gagal ginjal dan penyakit jantung seperti left ventricular hypertrophy dan congestive heart failure. 
Tabel 1: Karakteristik Responden $(n=50)$

\begin{tabular}{|c|c|c|}
\hline Karakteristik & & $\mathrm{n}(\%)$ \\
\hline Umur (Dalam tahun): & $<40$ tahun & $8(16)$ \\
\hline Mean: 58.12 & $40-60$ tahun & $30(60)$ \\
\hline & $>60$ tahun & $12(24)$ \\
\hline Jenis kelamin & Laki-laki & $9(18)$ \\
\hline & Perempuan & $41(82)$ \\
\hline Agama & Islam & $50(100)$ \\
\hline Suku & Madura & $43(86)$ \\
\hline & Jawa & $7(14)$ \\
\hline Status Pernikahan & Menikah & $48(96)$ \\
\hline & Janda & $2(4)$ \\
\hline Tingkat Pendidikan & Tidak Tamat SD/Tidak Sekolah & $6(12)$ \\
\hline & $\mathrm{SD}$ & $35(70)$ \\
\hline & SMP & $8(16)$ \\
\hline & SMA & $1(2)$ \\
\hline Pekerjaan & Petani & $35(70)$ \\
\hline & Wiraswasta & $4(8)$ \\
\hline & Ibu Rumah Tangga & $4(8)$ \\
\hline & Tidak Bekerja & $7(14)$ \\
\hline Pendapatan & $<\operatorname{Rp} 1.700 .000$ & $40(80)$ \\
\hline & $>1.700 .000-3.000 .000$ & $8(16)$ \\
\hline & $>3.000 .000$ & $2(4)$ \\
\hline Riwayat hipertensi dalam & Ada & $31(62)$ \\
\hline keluarga & Tidak ada & $19(38)$ \\
\hline informasi & Buku & $2(4)$ \\
\hline kesehatan & Berita & $10(20)$ \\
\hline & Pendidikan kesehatan & $5(10)$ \\
\hline & Tidak pernah mendapat informasi & $33(66)$ \\
\hline menderita & $<6$ bulan & $6(12)$ \\
\hline hipertensi & 6 bulan -2 tahun & $21(42)$ \\
\hline & $>2$ tahun & $23(46)$ \\
\hline
\end{tabular}

Tabel 2: Dukungan Keluarga dan Manajemen Hipertensi

\begin{tabular}{|c|c|c|c|c|c|c|c|c|c|}
\hline \multicolumn{10}{|c|}{ Manajemen Hipertensi } \\
\hline & & \multicolumn{2}{|c|}{ Baik } & \multicolumn{2}{|c|}{ Kurang } & \multicolumn{2}{|c|}{ Total } & \multirow[t]{2}{*}{$P$ value } & \multirow[t]{2}{*}{ Nilai $r$} \\
\hline & & $\mathrm{n}$ & $\%$ & $\mathrm{n}$ & $\%$ & $\mathrm{n}$ & $\%$ & & \\
\hline \multirow{2}{*}{$\begin{array}{c}\text { Dukungan } \\
\text { Keluarga }\end{array}$} & Baik & 24 & 48 & 2 & 4 & 26 & 52 & \multirow{3}{*}{0,02} & \multirow{3}{*}{0,540} \\
\hline & Kurang & 2 & 4 & 22 & 44 & 24 & 48 & & \\
\hline To & & 26 & 52 & 24 & 48 & 50 & 100 & & \\
\hline
\end{tabular}

Hipertensi yang tidak terkontrol dapat menimbulkan komplikasi yang berdampak pada sistem kardiovaskular dan serebrovaskular, ginjal dan retina yang sering disebut dengan kerusakan organ target. Kerusakan organ target tersebut seperti hipertrofi ventrikel kiri, peningkatan ketebalan intima media dari pembuluh darah, mikroalbuminuria yang mengikuti disfungsi 
glomerulus, penurunan kognitif dan retinopati hipertensi lalu terjadi komplikasi mayor, yaitu stroke, gagal jantung kongestif dan miokard infark, gagal ginjal dan oklusi vaskular retina (Kabedi, et.al, 2014).

Target pengobatan pasien hipertensi menurut Eighth Joint National Committee (JNC 8) adalah $<140 / 90 \mathrm{mmHg}$ untuk usia kurang dari 60 tahun dan $<150 / 90 \mathrm{mmHg}$ untuk usia 60 tahun keatas. Namun, pada pasien hipertensi yang disertai penyakit diabetes elitus atau penyakit ginjal kronik, target tekanan darah harus mencapai <140/90mmHg tanpa memandang usia pasien (James, et.al, 2014). Terapi pasien hipertensi diawali dengan intervensi gaya hidup, kemudian pemberian obatobatan. Modifikasi gaya hidup dapat menurunkan risiko penyakit lain dan menghindari kebutuhan terapi obat. Menjaga gaya hidup tetap sehat saja tidak cukup untuk menurunkan tekanan darah, kebanyakan pasien membutuhkan terapi farmakologi untuk mengontrol tekanan darah mereka.

Menurut JNC 8, gaya hidup yang dilakukan adalah membatasi merokokmengontrol diet dengan mengurangi konsumsi alkohol, membatasi sodium tidak lebih dari2.400 mg/hari, serta melakukan aktivitas fisik 3-4 hari per minggu dengan rata-rata 40 menit per sesi. Terapi obat-obatan dibutuhkan jika modifikasi gaya hidup tidak mencapai targettekanan darah secara adekuat.

Progresivitas hipertensi berkembang menjadi hypertension related disease dapat diturunkan dengan beberapa faktor seperti social support, environmental factors, dan familiy support. Dukungan keluarga atau Family support dibutuhkan pasien untuk mengontrol penyakit. Suatu penelitian di Brazil menemukan bahwa kelurga berpengaruh positif dalam mengontrol penyakit. Kesulitan dalam hubungan keluarga, perhatian keluarga terhadap keturunannya, dan keterlibatan kecil dalam perawatan pasien mempengaruhi kesembuhan pasien (Li, et.al, 2013). Pasien yang memiliki dukungan dari keluarga mereka menunjukkan perbaikan perawatan dari pada yang tidak mendapat dukungan dari keluarga. Dukungan keluarga dapat berupa perhatian mengenai penyakit mereka atau mengingatkan untuk minum obat (Olowookere, et.al, 2015).

Menurut Duvall, keluarga adalah sekumpulan orang yang dihubungkan oleh ikatan perkawinan, adopsi, kelahiran yang bertujuan menciptakan dan mempertahankan budaya yang umum, meningkatkan perkembangan fisik, mental, emosional, dan sosial dari tiap anggota keluarga. Keluarga merupakan lembaga pertama dalam kehidupan anak, tempat anak belajar dan mengatakan sebagai makhluk sosial. Keluarga adalah unit terkecil dari masyarakat yang terdiri dari suami, istri atau suami, istri dan anak atau ayah dan anak atau ibu dan anak. Dukungan keluarga merupakan sesuatu yang esensial untuk pasien dalam mengontrol penyakit (Bahari, 2019). Keluarga merupakan dukungan utama bagi pasien hipertensi dalam mempertahankan kesehatan (Nyaaba, et.al, 2019). Keluarga memegang peran penting dalam perawatan maupun pencegahan kesehatan pada anggota keluarga lainnya. Oleh sebab itu, keluarga harus memiliki pengetahuan tentang hal tersebut. Pengetahuan keluarga mengenai penyakit 
hipertensi merupakan hal yang sangat penting. Apabila pengetahuan keluarga semakin baik maka perilakunya akan semakin baik. Namun, jika pengetahuan yang baik tidak disertai dengan sikap, maka pengetahuan itu tidak akan berarti (Grant, 2013).

Keluarga memiliki peran dalam manajemen penyakit pasien, dimulai dari makan harian, aktivitas fisik, serta manajemen stres. Anggota keluarga memutuskan makanan apa yang akan dikonsumsi, aktivitas fisik yang sesuai dan bagaimana kesehatan menjadi prioritas dalam keluarga (Rosland, 2009). Penanganan hipertensi dari sisi asupan makanan dimulai dengan pembatasan natrium dan lemak dalam diet, pengaturan berat badan (jumlah kalori sesuai dengan BMI), perubahan gaya hidup, program latihan, dan tindak lanjut asuhan kesehatan dengan interval teratur. Ketidak patuhan terhadap program terapi merupakan masalah yang besar pada penderita hipertensi. Bila pasien berpartisipasi secara aktif dalam program termasuk pemantauan diri mengenai tekanan darah dan diet, kepatuhan cenderung meningkat karena dapat segera diperoleh umpan balik sejalan dengan perasaan semakin terkontrol (Susanto, 2016; Suprianto, et.al, 2009).

Anggota keluarga juga memberikan dukungan emosional yang membantu pasien untuk menangani stres akibat penyakitnya. Ketika keluarga memberikan dukungan kepada pasien, maka keadaan pasien akan membaik. Dukungan keluarga yang meningkat akan berhubungan dengan kontrol tekanan darah yang lebih baik pada pasien hipertensi (Leelacharas, 2005). Dukungan emosional keluarga terlihat dimana keluarga sebagai tempat yang aman dan damai untuk istirahat dan belajar serta membantu penguasaan terhadap emosi, diantaranya menjaga hubungan emosional meliputi dukungan yang diwujudkan dalam bentuk afeksi, adanya kepercayaan, perhatian dan mendengarkan atau didengarkan saat mengeluarkan perasaanya (Efendi \& Larasati, 2017).

Harmonitas

keluarga diperlukan dalam menurunkan mortalitas penyakit hipertensi, dimana dengan menurunnya tingkat stress kejadian peningkatan tekanan darah dapat dimungkinkan untuk menurun. Keseimbangan finansial sangat diperlukan dimana terapi dalam hipertensi bersifat kontinus. Sehingga keseimbangan finansial sangat diperlukan untuk mempertahankan terapi yang sedang dilaksanakan. Dalam kontrol kesehatan sangat diperlukan dukungan keluarga. Dikarenakan keluarga berperan sebagai suatu kelompok utama yang bertindak sebagai pengingat. Dukungan keluarga juga memiliki peran bersamaan dengan manajemen diri dalam mengontrol penyakit kronik. Keluarga memberikan peranan penting dalam mendorong dan memperkuat perilaku pasien.

\section{SIMPULAN}

Sebagian besar klien hipertensi dalam penelitian ini ternyata memiliki manajemen hipertensi yang masih rendah. Sebagian besar mempunyai tingkat pendidikan rendah dengan status perekonomian juga rendah. Rendahnya tingkat pengetahuan disebabkan juga salah satunya adalah sebagian besar mereka belum mendapatkan 
informasi kesehatan yang cukup. Dalam penelitian ini juga diketahui bahwa dukungan keluarga terhadap manajemen hipertensi anggota keluarganya juga rendah. Hal ini juga menjadi salah satu penyebab rendahnya manajemen hipertensi yang dilakukan oleh klien hipertensi. Dengan demikian semakin rendah dukungan keluarga maka perilaku manajemen hipertensi klien hipertensi juga kurang baik yang mengakibatkan hipertensi tidak terkontrol. Hal ini tentu membutuhkan strategi yang tepat untuk meningkatkan dukungan keluarga agar pengobatan hipertensi berhasil dan menurunkan risiko komplikasi.

\section{SARAN}

1) Petugas kesehatan disarankan melakukan optimalisasi dukungan keluarga melalui kunjungan rumah secara rutin untuk memantau manajemen hiupertensi. Optimalisasi dukungan keluarga ini dapat dilakukan melalui edukasi bersama seluruh anggota keluarga, pemantaua secara berkala aktivitas keluarga melalui kunjungan rumah, dan memperbanyak sharing session dengan petugas kesehatan; 2) Puskesmas dapat menyusun program kunjungan keluarga untuk mengoptimalkan dukungan keluarga untuk meningkatkan perawatan pada penderita hipertensi. Salah satu program tersebut dapat menjadi target utama dalam program pemberantasan penyakit; 3) Dinas Kesehatan sebagai koordinator utama dalam setiap kegiatan Puskesmas dapat melakukan follow up secara berkala terkait kunjungan keluarga yang berjalan di puskesmas untuk mengoptimalkan jumlah kunjungan keluarga yang dilakukan oleh
Puskesmas; 4) Hasil dari penelitian ini dapat menjadi acuan bagi peneliti selanjutnya untuk melakukan penelitian mengenai intervensi untuk optimalisasi dukungan keluarga dalam meningkatkan manajemen hipertensi.

\section{DAFTAR PUSTAKA}

Li, G., Hu, H., Dong, Z., \& Arao, T. (2013). Development of the chinese family support scale in a sample of chinese patients with hypertension. PLoS

One, 8(12) doi:http://eresources.perpusnas.go.id:216 6/10.1371/journal.pone.00856 82

Olowookere, A., Olowookere, S., Talabi, A., Etonyeaku, A., Adeleke, O., \& Akinboboye, O. (2015). Perceived family support and factors influencing medication adherence among hypertensive patients attending a nigerian tertiary hospital. Annals of Tropical Medicine and Public Health, 8(6) doi:http://eresources.perpusnas.go.id:216 6/10.4103/1755-6783.162668

Bahari, G. M. (2019). Family social support, self-efficacy, and self-care behaviors among saudi adult males with hypertension in saudi arabia (Order No. 13878209). Available from ProQuest Dissertations \& Theses Global: The Humanities and Social Sciences Collection. (2247120043). Retrieved from https://eresources.perpusnas.go.id:235 
0/dissertations-theses/familysocial-support-self-efficacycare/docview/2247120043/se2 ? accountid $=25704$

Stabile, E., Izzo, R., Rozza, F., Losi, M. A., De Luca, N., \& Trimarco, B. (2017). Hypertension survey in italy: Novel findings from the campania salute network. High Blood Pressure \& Cardiovascular Prevention, 24(4), 363-370. doi:http://e-

resources.perpusnas.go.id:216 6/10.1007/s40292-017-02205

Grant, A. M. (2013). Hypertension knowledge, expectation of care, social support, and adherence to prescribed medications of african americans with hypertension framed by the roy adaptation model (Order No. 3561785). Available from Publicly Available Content Database. (1366760616). Retrieved from https://eresources.perpusnas.go.id:235 $0 /$ dissertationstheses/hypertensionknowledge-expectation-caresocial/docview/1366760616/s e-2? accountid $=25704$

Nyaaba, G. N., Stronks, K., Meeks, K., Beune, E., Ellis OwusuDabo, Addo, J., . . . Agyemang, C. (2019). Is social support associated with hypertension control among ghanaian migrants in europe and non-migrants in ghana? the RODAM study. Internal and Emergency Medicine, 14(6), $\quad$ 957-966. doi:http://eresources.perpusnas.go.id:216 6/10.1007/s11739-01902075-7

Cornwell, E. Y., \& Waite, L. J. (2012). Social network resources and management of hypertension. Journal of Health and Social Behavior, 53(2), 215-31. doi:http://eresources.perpusnas.go.id:216 6/10.1177/002214651244683 2

Ademe, S., Aga, F., \& Gela, D. (2019). Hypertension selfcare practice and associated factors among patients in public health facilities of dessie town, ethiopia. BMC Health Services

Research, 19 doi:http://eresources.perpusnas.go.id:216 6/10.1186/s12913-019-38800

Leelacharas, S. (2005). Illness representations in thai women diagnosed with hypertension and relationships to medicationtaking behavior(Order No. 3192702). Available from ProQuest Dissertations \& Theses Global: The Humanities and Social Sciences Collection. (305455765). Retrieved from https://e-

resources.perpusnas.go.id:235 0/dissertations-theses/illnessrepresentations-thai-womendiagnosedwith/docview/305455765/se2? accountid $=25704$

Hedner T, Kjeldsen SE, Narkiewicz K. State of global health hypertension burden and control. Blood Press. 2012;21(Suppl 1):1-2. 
Mills KT, Bundy JD, Kelly TN, Reed JE, Kearney PM, Reynolds K, Chen J, He J. Global disparities of hypertension prevalence and control: a systematic analysis of population-based studies from 90 countries. Circulation. 2016; 134:44150.

Chobanian AV, Bakris GL, Black HR, Cushman WC, Green LA et al. (2003) The Seventh Report of the Joint National Committee on Prevention, Detection, E valuation, and Treatment of High Blood Pressure: the JNC 7 report. JAMA 289: 2560-2572. doi:10.1001/jama.

289.19.2560

PubMed: 12748199.

Hamer M, Batty GD, Stamatakis E, Kivimaki M (2010) Hypertension awareness and psychological distress. Hypertension 56: 547-550. doi:

10.1161/HYPERTENSIONA HA.110.153775. PubMed: 20625078.

Johansen A, Holmen J, Stewart R, Bjerkeset O (2012) Anxiety and depression symptoms in arterial hypertension: the influence of antihypertensive treatment. The HUNT study, Norway. Eur J Epidemiol 27: 63-72. doi:10.1007/s10654011-9641-y.

PubMed: 22183137

Kabedi NN, Kayembe DL, Kayembe TK. Hypertensive retinopathy and its association with cardiovascular, renal and cerebrovascular morbidity in congolese patients. Cardiovasc J Afr [internet]. 2014; 25: 228-32.

James PA, Oparil S, Carter BL, Cushman WC, DennisonHimmelfarb C, Handler J, et al,. Guideline for the management of high blood pressure in adults: report from the panel members appointed to the eighth joint national committee. $J A m$ Med Assoc [internet]. 2014

Rosland AM. Sharing the care: the role of family in chronic illness [internet]. California Healthcare Foundation; 2009

Susanto Y. Hubungan dukungan keluarga dengan kepatuhan minum obat pasien hipertensi lansia di wilayah kerja puskesmas sungai cuka kabupaten tanah laut. Jurnal Ilmiah Manuntung [internet]. 2015 [disitasi tanggal 4 Oktober 2016]; 1(1):62-67.

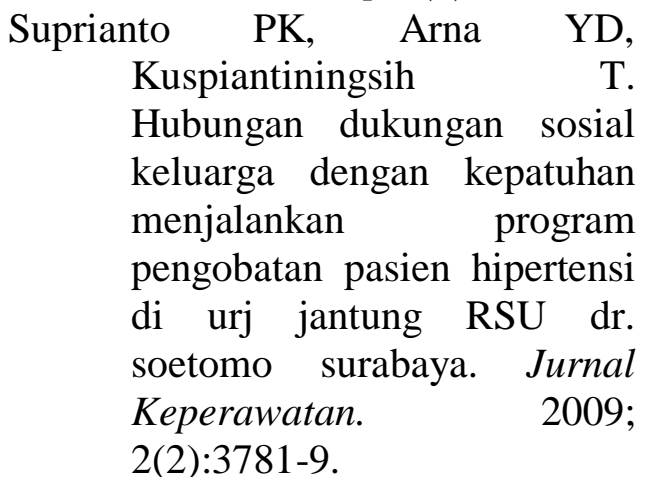

